Faculdade de Ciências Econômicas da UFRGS
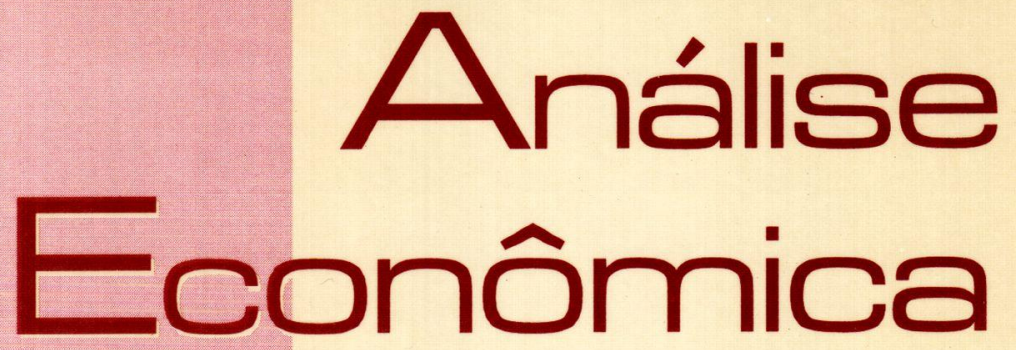

A Instabilidade Financeira dos Anos 90: Alqumas Implicações para as Economias Capitalistas Periféricas André Cunha e Daniela Prates

A Ampliação Recente da Participação Estrangeira no Sistema Bancário Brasileiro Maria Cristina Penido de Freitas

INFRA-ESTRUTURA dE INfORMAÇÕES E SISTEMA Nacional de InOvação

Eduardo da Motta e Albuquerque

Custo Social dos Recursos Hídricos em Bacias Hidrográlicas Internacionais: O Caso da Bacia do Paraná Jandir Ferrera de lima e José Carrera-Fernandez

Preferência pela liovidez e Escollha de Porrtólio

José Luis Oreiro

Eficiência, Objetivo e Coordenação da Política Macroeconômica no Período: 1974 - 1979

JoÃo Sicsú

Macroeconomia Moderna: Keynes e a ECONOMIA CONTEMPORÂNEA - Resenha

Simone Silva de Deos

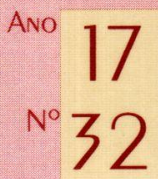


Universidade Federal do Rio Grande do Sul

Reitora: Proft. Wrana Maria Panizzi

Faculdade de Ciências Econômicas

Diretora: Prof ${ }^{a}$. Otilia Beatriz Kroeff Carrion

Centro de Estudos e Pesquisas Econômicas

Diretor: Prof. Fernando Ferrari Filho

Departamento de Ciencias Econômicas

Chefe: Prof Luiz Alberto Oliveira Ribeiro de Miranda

Curso de Pós-Graduação em Economia

Coordenador: Prof. Marcelo Savino Portugal

Curso de Pós-Graduaçāo em Economia Rural

Coordenador: Prof. Carlos Guilherme A. Mielitz Netto

Conselho edtrorial

Achyles B. Costa, Aray M. Feldens, Carlos A. Crusius, Carlos G. A. Mielitz Netto, Eduardo A. Maldonado Filho, Eduardo P. Ribeiro, Eugênio Lagemann, Fernando Ferrari Filho, Gentil Corazza, Marcelo S. Portugal, Nali J. Souza, Otilia B. K. Carrion, Paulo A. Spohr, Paulo D. Waquil, Pedro C. D. Fonseca, Roberto C. Moraes, Ronald Otto Hillbrecht, Stefano Florissi, Eleutério F. S. Prado (USP), Fernando H. Barbosa (FGV/RJ), Gustavo Franco (PUC/RJ), João R Sanson (UFSC), Joaquim P. Andrade (UnB), Juan H. Moldau (USP), Paul Davidson (Univ. of Tennessee), Werner Baer (Univ. of Illinois).

Comissão EDITORLAL

Eduardo Augusto Maldonado Filho, Fernando Ferrari Filho, Gentil Corazza, Marcelo Savino Portugal, Paulo Dabdab Waquil; Roberto Camps Moraes.

EDrTor: Gentil Corazza

Edrror Adjunto: Pedro Silveira Bandeira

SeCretaria: Laize Espindula.

REVISÃo DE TEXTos: Vanete Ricacheski.

Fundador: Prof. Antônio Carlos Santos Rosa

Os materiais publicados na revista Análise Econômica são da exclusiva responsabilidade dos autores. É permitida a reprodução total ou parcial dos trabalhos, desde que seja citada a fonte. Aceita-se permuta com revistas congêneres. Aceitam-se, também, livros para divulgação, elaboração de resenhas e recensões. Toda correspondência, material para publicação (vide normas na terceira capa), assinaturas e permutas devem ser dirigidos ao seguinte destinatário:

Prof, Gentul Corazza

Revista Análise Econômica - Av. João Pessoa, 52 CEP 90040-000 PORTO ALEGRE - RS, BRASIL

Telefones: 0xx (51) 316-3348 e 316-3440 - Fax: 0xx (51) 316-3990 rae@vortex.ufrgs.br

Análise Econômica

Ano 17, n. 32, setembro, 1999 - Porto Alegre

Faculdade de Ciências Econômicas, UFRGS, 1999

Periodicidade semestral, março e setembro.

ISSN 0102-9924

1. Teoria Econômica - Desenvolvimento Regional -

Economia Agrícola - Pesquisa Teórica e Aplicada -

Periódicos. I. Brasil.

Faculdade de Ciências Econômicas,

Universidade Federal do Rio Grande do Sul.

CDD 330.05

CDU 33 (81) (05) 


\section{Macroeconomia de inspiração Keynesiana}

Simone Silva de Deos*

Apesar do que o título possa sugerir ao leitor desavisado, Macroeconomia Moderna: Keynes e a economia contemporânea (Rio de Janeiro, Campus, 1999) não é, e não pretende ser, um manual de macroeconomia. Sendo assim, não se deve buscar no livro a tradicional seqüência de capítulos que leva os estudantes de graduação, no curso de Macroeconomia, da contabilidade nacional, aos diferentes modelos macroeconômicos. O objetivo básico do livro, conforme apontam seus organizadores - Gilberto Tadeu Lima, João Sicsú e Luiz Fernando de Paula - é demonstrar a relevância da abordagem keynesiana/ pós-keynesiana para a análise de diversos temas no âmbito da economia.

Pode ser interessante situar o leitor em potencial a respeito do debate em que se insere o livro, dentro da teoria econômica. Na literatura da área, a expressão keynesianos está tradicionalmente associada aos adeptos da chamada síntese neoclássica e aos propositores das políticas macroeconômicas que derivaram desta e foram muito populares dos anos 50 até os 70 . A formalização que foi feita da Teoria Geral de Keynes, que ficou amplamente conhecida como modelo IS-LM, acabou tornado-se o próprio símbolo da síntese neoclássica, dos "velhos keynesianos".

Mais recentemente, o grupo de autores conhecidos como novos-keynesianos forma o mainstream, o pensamento ortodoxo predominante. A escola surge na década de 80 em reação à supremacia monetarista vigente, disputando com a economia novo-clássica o status de corrente principal. Seus esforços são no sentido de modelar a velha macroeconomia keynesiana atendendo às duas críticas fundamentais dos novos-clássicos: a não inclusão de expectativas (racionais) em seus modelos e a falta de microfundamentos dos mesmos. A preocupação principal da escola é explicar rigidez de preços e falhas de mercado.

Contudo o conteúdo keynesiano predominante neste livro não está diretamente associado ao que se possa chamar de novo ou velho keynesianismo. De fato, várias contribuições aqui reunidas podem ser rotuladas como póskeynesianas. Estilizadamente, pode-se dizer que esta escola caracteriza-se pela rejeição da leitura e interpretação dos "velhos e novos" keynesianos quanto à existência e às causas do desemprego involuntário, tema central da Teoria Geral. Os pós-keynesianos resgatam o que Keynes chamou de princípio da demanda efetiva, segundo o qual os níveis de produção e emprego são estabelecidos em função da expectativa de lucro dos empresários. Também preocupam-se em recuperar e desenvolver aspectos da teoria de Keynes que estão postos ou podem ser inferidos da Teoria Geral, mas têm sido sistematicamente

* Mestre em Economia pelo IEPE - UFRGS e Doutoranda de IE - UNICAMP. 
desconsiderados pelos keynesianos ortodoxos. Entre esses, merecem destaque a necessidade de colocar a análise econômica novamente no tempo e de incorporar, com ênfase, a incerteza e a moeda. Contudo, nem todas as contribuições aqui reunidas podem ser enquadradas sob o rótulo mais estrito do póskeynesianismo, ainda que resgatem insights originais de Keynes e longe estejam de um enquadramento mais ortodoxo.

Não sendo um manual de macroeconomia, o livro pretende ser mais que uma coletânea de artigos de "genuína inspiração keynesiana". Busca articular contribuições originárias de diferentes autores em três partes, correspondentes a distintas áreas temáticas. Assim, numa seqüência lógica, a primeira trata de teoria pura, dos chamados Fundamentos Teóricos dessa "economia keynesiana". Isto feito, a parte seguinte versa sobre um tema fundamental e que costuma receber atenção especial e apresenta desenvolvimentos interessantes no póskeynesianismo: Sistema Financeiro, Financiamento e Crescimento. A terceira e última parte trata de Dinâmica Econômica, Políticas Macroeconômicas e Crises Monetárias. Passemos a uma avaliação mais detalhada.

O primeiro capítulo, de autoria de Paul Davidson, faz a crítica à visão keynesiana ortodoxa (aquela que, a propósito, costuma frequientar as páginas dos tradicionais manuais de macroeconomia) e argumenta porque seria esta incompatível com a contribuição de Keynes. Nesse sentido, procura justificar a necessidade e relevância da abordagem pós-keynesiana. $O$ capítulo seguinte, cujo autor é Luiz Antônio de Oliveira Lima (FGV-SP), avança para uma discussão teórica contemporânea, matematicamente formalizada (e instigada, a propósito, pela ortodoxia), acerca da necessidade de microfundamentação da macroeconomia. Conclui, de forma muito interessante e em oposição frontal ao mainstream, pela necessidade de macrofundamentar a microeconomia. Segue-se a este o terceiro capítulo, de autoria de David Dequech (UNICAMP), que levanta uma das "bandeiras" da escola pós-keynesiana, afirmando que a incerteza, em oposição à noção convencional de risco probabilístico, é um elemento central e estrutural da economia capitalista.

O quarto capítulo, de autoria de Carmem Aparecida Feijó (UFF), introduz a noção de expectativas, essencial no pensamento que deriva de Keynes, pois intimamente vinculada à necessidade de tomada de decisões empresariais - de produção, investimento e financiamento - num mundo de incerteza. A reflexão final dessa primeira parte está no capítulo de número cinco, escrito por Fernando Nogueira da Costa (UNICAMP), que trata de uma polêmica interna ao pós-keynesianismo no âmbito da teoria monetária. Discute preferência pela liquidez e formato da curva de oferta de moeda, questões que dividem os pós-keynesianos em duas correntes: fundamentalismo $\mathrm{x}$ horizontalismo. $\mathrm{O}$ autor advoga, apoiado na teoria do circuito monetário, uma possibilidade de compatibilização entre estas. 
A segunda parte do livro trata de Sistema Financeiro, Financiamento e Crescimento. Esses temas, essenciais para a compreensão do funcionamento das economias contemporâneas - e que, num aparente paradoxo, nem sempre têm a devida atenção no âmbito da teoria econômica, sobretudo no chamado mainstream - encontram aqui, sob a égide do pós-keynesianismo, espaço privilegiado. Merece destaque o primeiro capítulo dessa Parte II e sexto do livro, de autoria de Rogério Studart (UFRJ), que discute o papel das instituições e mercados financeiros no funcionamento das economias capitalistas, apontando seu caráter crucial. Chamamos atenção, ainda, para a oportuna discussão sobre o papel da poupança macroeconômica para o investimento. $O$ sétimo capítulo, escrito por Luiz Fernando de Paula (UERJ-UCAM), aprofunda o mesmo tema, buscando analisar o comportamento dos bancos e seus efeitos sobre a oferta de crédito.

Ainda nesta segunda parte, o capítulo seguinte, oitavo do livro, interrompe a sequiência de temas da órbita monetária, chamando atenção para outra questão fundamental para a compreensão da dinâmica das economias capitalistas - questão que é também, em boa medida, "renegada" no mainstream. Gilberto Tadeu Lima (UNICAMP), seu autor, apresenta um modelo de acumulação de capital, crescimento e distribuição de renda cuja trajetória é influenciada por um processo endógeno de inovação tecnológica. A compreensão do conteúdo aqui exposto exigirá dos leitores familiaridade com uma linguagem matemática não trivial, uma vez que o modelo é formalmente apresentado.

O capítulo nove, de autoria de Adriana Moreira Amado (UNB), retoma os temas de economia monetária, mas dentro de uma perspectiva de desenvolvimento regional. Propõe uma análise para o pouco discutido processo de concentração bancária no país, e conclui que tal processo pode aprofundar as desigualdades regionais. O décimo capítulo, escrito por José Luís Oreiro (IBMEC), conclui essa parte do livro. Discute teoricamente os determinantes da taxa de juros, resgatando o debate entre Keynes e os clássicos.

A terceira e última parte do livro trata de Dinâmica Econômica, Políticas Macroeconômicas e Crises Monetárias. É dessa dinâmica econômica e sua inevitável dimensão financeira que versa, a propósito, o primeiro capítulo dessa parte, décimo primeiro do livro. Agregando as contribuições de Kalecki e Steindl às de Keynes, Luiz Gonzaga Belluzzo e Júlio Sérgio Gomes de Almeida (UNICAMP), seus autores, acrescentam à análise um novo "eixo", através da introdução da categoria dos rentistas, indagando-se sobre como seu comportamento afeta o funcionamento da economia. No final desse capítulo no qual a complexidade teórica é muito mais que compensada pela riqueza dos insights oferecidos, propiciam uma oportuna análise da crise financeira do Estado, sua 
gênese, tensões, limites e conseqüências, para além do imediato.

No décimo segundo capítulo, de autoria de Fernando Cardim de Carvalho (UFRJ), passa-se explicitamente para o âmbito da política econômica. Na introdução faz-se uma reflexão importante e oportuna sobre a dimensão política da crítica vulgar ao keynesianismo. A partir daí, o capítulo tem como objetivo recuperar a abordagem de política econômica desenvolvida originalmente por Keynes. Conclui, sem muita surpresa, que há um viés intervencionista nessa abordagem, coerente com a análise teórica. Ainda no âmbito da política econômica está o capítulo de número treze, escrito por João Sicsú (UFF), que trata de um tema específico dentro da política monetária. Incorporando uma temática introduzida originalmente pelos novos-clássicos, discute a questão da reputação dos dirigentes do banco central e seu impacto, via expectativa dos agentes, sobre a eficácia destas políticas.

O décimo quarto capítulo trata de um tema bem contemporâneo: o fenômeno das crises cambiais. Joaquim Pinto de Andrade e Maria Luiza Falcão Silva (UNB), seus autores, fazem uma comparação de diferentes abordagens teóricas para tal fenômeno. E a interessante, quiçá promissora conclusão, é que o mainstream e a abordagem pós-keynesiana têm conduzido a resultados muito semelhantes, talvez complementares, sobre a questão. Ainda dentro desta temática das crises financeiras internacionais, o décimo quinto capítulo do livro, de autoria de Fernando Ferrari Filho (UFRGS), pretende resgatar as contribuições originais de Keynes sobre o tema, num momento em que se discute uma "nova arquitetura financeira mundial".

O décimo sexto e último capítulo do livro traz diferenças significativas em relação aos demais. Paulo Nogueira Batista Jr. (FGV-SP), seu autor, não está tratando temas contemporâneos da agenda teórica. Apresenta e discute as reflexões e propostas de Keynes sobre a hiperinflação e a estabilização do marco alemão, acontecimentos do início dos anos 20. Contudo, como coloca seu autor, $o$ interesse do capítulo transcende a dimensão histórica, pois antecipa em vários pontos discussões recentes sobre inflação, hiperinflação e planos de estabilização. Para além da exegese pura e simples, pela qual os póskeynesianos são muitas vezes - e em algumas adequadamente - criticados, traz à tona uma reflexão importante e pouco conhecida de Keynes.

Como obra coletiva, Macroeconomia Moderna manifesta vícios e virtudes. As diferentes filiações, preocupações e linguagens dos autores são perceptíveis no livro, em que cada capítulo tem personalidade e estatura própria. Mas é sem dúvida relevante e oportuna a iniciativa de reunir e disponibilizar a um público maior as contribuições de importantes economistas brasileiros exceção feita ao capítulo inicial, de autoria do norte-americano Paul Davidson, considerado o grande expoente da escola. A obra demonstra o vigor, a amplitu- 
de e, em alguns casos mais explicitamente, a qualidade e originalidade da produção acadêmica nacional, que não deve permanecer confinada às revistas científicas de circulação restrita. E é uma oportunidade para refletirmos, uma vez mais, sobre a produção doméstica de teoria, inclusive da teoria pura, que é sistematicamente posta em dúvida. Ainda que, num aparente contra-senso, a bibliografia referida pela grande maioria dos autores deste livro pouco cite seus "parceiros" brasileiros, que já há algum tempo produzem trabalhos de qualidade na área.

Por tudo isso, o livro é recomendável a todos que pretendam amadurecer suas reflexões em economia. Mas que não se espere uma "leitura fácil", pois o leitor se defrontará com trabalhos cuja linguagem nem sempre é imediatamente acessível. De outro lado, a possibilidade de acesso deste leitor às controvérsias teóricas presentes no livro pode ajudá-lo a refletir sobre as dificuldades de fazer teoria e compreender, assim, que a ciência é um processo em aberto, do qual o debate é parte irrevogável. Sendo assim, a palavra final sempre estará por ser dita. Além do que, e para o bem da ciência econômica, é urgente que esse debate seja mais pluralista. Com isso queremos dizer que todas as contribuições heterodoxas de qualidade são bem-vindas e oportunas. 